\title{
Seismic analysis of the zaouiat ait mellal twin tunnels of Agadir motorway (Morocco)
}

\author{
Abdelhay El Omari ${ }^{1,}{ }^{*}$, Mimoun Chourak ${ }^{1}$, Carlos Navvaro Ugena ${ }^{2}$, Seif-Eddine Cherif ${ }^{3}$, Mohamed Rougui ${ }^{4}$, \\ Hassan Bakali ${ }^{5} \&$ Angel luis Sanchez-Merino ${ }^{6}$ \\ ${ }^{1}$ Mechanics and applied mathematics department, Industrial and Seismic Engineering research team ,National School of \\ Applied Sciences of Oujda ,Mohammed First University,Morocco. \\ ${ }^{2}$ Continuum Mechanics and Structural Analysis department, Carlos III University of Madrid, Spain. \\ ${ }^{3}$ Laboratoire de Géoressources, Géo-environement et Génie Civil (LGGG), Faculty of Sciences and Technologies of Marrakesh, \\ Cadi Ayyad University, Morocco. \\ ${ }^{4}$ LGCE, Ecole supérieure de technologie de Salé, Mohammed V University, Morocco. \\ ${ }_{6}^{5}$ Laboratoire Public d'Essais et d'Etudes LPEE de l'oriental, Morocco. \\ 6 Sener Ingerieria y Sistemas S.A ,Spain
}

\begin{abstract}
Underground structures, such as tunnels, are vital for ensuring all kinds of transportation; and being buried under the surface makes them exposed to soil dynamics. Added to the moderate seismic activity in Morocco, the stability of tunnels is put to the test. This paper examines the interaction between the ZAM (Zaouit Ait Mellal) twin tunnels between the cities of Marrakesh and Agadir, using the Difference Element Method provided by FLAC 2D software. The acceleration is introduced as the one related to the historic event of El centro 1940 with free-field boundary conditions in the numerical model, with three configurations: tunnel 1 without tunnel 2, tunnel 2 without tunnel 1 and tunnel 1 with tunnel 2. The results of the simulations indicate that the differences values of the maximum displacement, axial force and bending moment on structural elements are very noteworthy from the configuration of the tunnel (single) to the twin tunnels in order to prove the interaction between these latter under seismic loading. Keywords: ZAM twin tunnels, finite difference method, seismic loading, Free filed boundary, displacement, Axial force, bending moment.
\end{abstract}

\section{Introduction}

In recent years, Morocco has experienced considerable development in infrastructure with the implementation of large projects such as road and rail networks and underground structures. However, the latter, in particular tunnels built in areas exposed to seismic activities must be particularly and essentially resistant to soil dynamics. This fact is illustrated in many cases of tunnel damage due to seismic events, such as the ones observed during the 1995 Kobe earthquake in Japan at the Daikai subway station [1-2], the 1999 Chi Chi earthquake in Taiwan investigated by Wang et al [3], which showed the 49 tunnels of 57 (in total) sustained damage from this earthquake and the 1999 Kocaeli earthquake in Turkey at of the Bolu tunnel [4].

The importance and cost of the underground $\mathrm{RC}$ structures require an accurate analysis of the seismic behavior of structural systems, including the ground environment. Although several studies have investigated the seismic performance of tunnels [5-9], little research has been conducted in northern Africa and Morocco.
Historically Morocco had experienced a very violent earthquake in 1960 in the city of Agadir of magnitude 5.7 on the Richter scale and which caused 12000 of deaths and $70 \%$ of the infrastructures are destroyed [10], For this reason, we chose the ZAM twin tunnels which are between Marrakech and Agadir motorway.

This article presents a seismic analysis of the ZAM twin tunnels, using the numerical simulation of the explicit finite difference method provided by FLAC 2D (Fast Lagrangian Analysis of Continua) (FLAC 2005 ) [11], software by introducing the data of El centro 1940 earthquake to see his impact between the tunnels on the maximum displacements in different points on structural elements, for that we chose 3 configurations as follows:

-Tunnel 1 without tunnel 2

-Tunnel 2 without tunnel 1

-Tunnel 1 with tunnel 2

\section{Data and Material}

\subsection{Technical Characteristics}

Corresponding author: elomari_abdelhay1718@ump.ac.ma 
The ZAM is the first twin tunnel motorway across the Atlas mountains, this tunnel is located between Marrakech and Agadir cities with total length of 546 (m), the RC tunnels lining is of horseshoe shape of $11 \mathrm{~m}$ wide $\mathrm{x} 9 \mathrm{~m}$ height without equipment and the distance between the tube centrelines is $26,5(\mathrm{~m})$.

\subsection{Geology}

The tunnel crosses a sedimentary rock formation from the Eocene and cretaceous periods, predominantly limestone (Figure 1), from the top to the bottom, the materials are as follow:

-Marls and marly limestone Massive brown limestone (type I)

-Massive limestone locally vacuolar and siliceous ( type II and IIII)

-Limestone with fragmented nodules ( type IV and V)

-Partially fractured to fractured light brown limestone (type VI)

-Marly limestone and grey-brown marls (type VII)

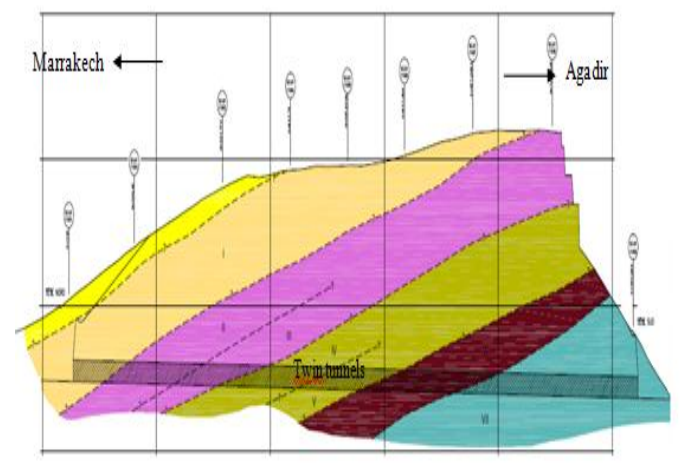

Fig.1. Longitudinal geological and geotechnical profile

\subsection{Soils and structural elements properties}

Table 1 summarized the properties of the soil layers following these distributions as mentioned in the longitudinal geotechnical profile (Figure 1) used in the numerical model, which are Young's modulus (E), Poisson's ratio (v), Cohesion ( c ), Friction angle $(\varphi)$, Dilation angle $(\psi)$ and unit weight $(\gamma)$.

Table.1. Geotechnical properties

\begin{tabular}{|c|c|c|c|c|c|c|}
\hline Soil & E GPa $)$ & $v$ & $\mathrm{c}(\mathrm{kPa})$ & $\begin{array}{c}\varphi \\
(\circ)\end{array}$ & $\begin{array}{c}\psi \\
(\circ)\end{array}$ & $\begin{array}{c}\gamma \\
\left(\mathrm{KN} / \mathrm{m}^{3}\right)\end{array}$ \\
\hline I & 25 & 0.3 & 1300 & 50 & 5 & 25 \\
\hline II & 35 & 0.3 & 1500 & 50 & 5 & 25 \\
\hline III & 15 & 0.3 & 1000 & 45 & 5 & 25 \\
\hline IV & 5 & 0.3 & 500 & 32 & 5 & 25 \\
\hline V & 8 & 0.3 & 700 & 35 & 5 & 25 \\
\hline VI & 15 & 0.3 & 1000 & 45 & 5 & 25 \\
\hline VII & 2.4 & 0.3 & 200 & 28 & 0 & 25 \\
\hline
\end{tabular}

For the RC tunnel lining, material is considered to be linear elastic, the proprieties are as follow:
-Young's Modulus (Pa) : 2e11

-Poisson's ratio : 0.2

-Density ( $\mathrm{kg} / \mathrm{m} 3$ ): 2500

-Inertia (m4) 2.3e-5

-Thickness (m) : 0.35

\section{Numerical modeling}

Analyses are conducted using the difference element method. The model is created with the FLAC 2D code on cross section of $89 \mathrm{~m}$ wide $\mathrm{x} 111 \mathrm{~m}$ height, the tunnel lining as elastic linear material using "liner " and "'beam" structural elements : and the different layers of soil are considered as a linear elastic-perfectly plastic material that follows the Mohr-Coulomb criterion. For the boundary conditions, we applied an absorbing boundaries at the sides of the model to minimize the seismic waves reflection in dynamic loading. FLAC employs a special lateral boundary known as free field as shown in figure 2 .

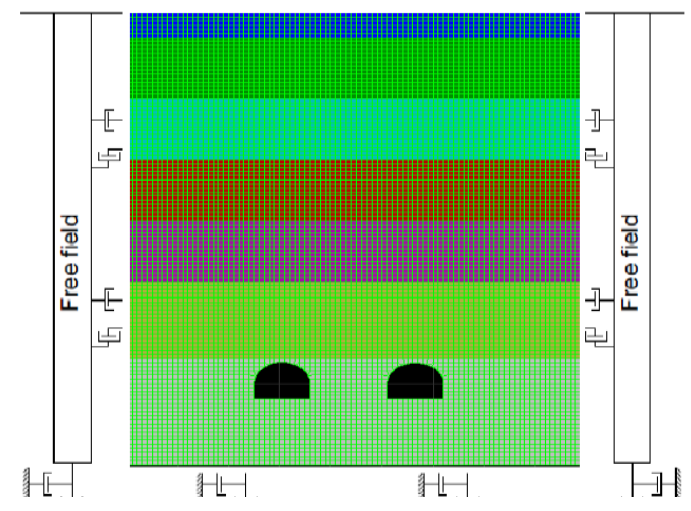

Fig .2. Constitutive model in FLAC with free-field boundaries

Concerning the dynamic Input, we have applied in the base of the model an acceleration time history of El centro 1940 earthquake (Figure 3) like an approximate way. This earthquake had a moment magnitude of 6.9 and a maximum perceived intensity of $\mathrm{X}$ (Extreme) on the Mercalli intensity scale (table 2). It was the first major earthquake to be recorded.

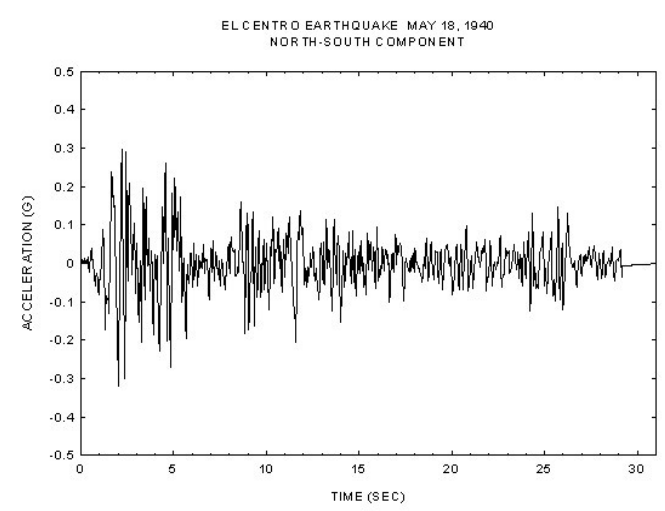

Fig.3.El Centro 1940 Earthquake accelerogams 
Table.2. Characteristic of input motion wave (Source : Pacific Earthquake Research Center)

\begin{tabular}{|c|c|}
\hline \multicolumn{2}{|l|}{ Earthquake motion parameters El Centro (USA) } \\
\hline Date of occurrence & 1940 \\
\hline Magnitude of earthquake, Mw & 6.9 \\
\hline Maximum horizontal acceleration, (g) & 0.349 \\
\hline Predominant period, Tp (s) & 0.56 \\
\hline Hypocentral distance (km) & 15.69 \\
\hline Arias intensity (m/s) & 1.758 \\
\hline
\end{tabular}

\section{Results and discussion}

The numerical simulation under seismic loading have been done, and the results are in terms of maximum displacement, Axial force and bending moment in the structure elements at dynamic time of $8.14 \mathrm{~s}$, due to the location of the Peak Ground Acceleration value in the accelerograms in the range $[0 \mathrm{~s}, 8 \mathrm{~s}]$. The estimation of these parameters around the tunnel requires special attention because it has a major influence on the design of lining, also for the verification of stability.

The figures 4, 5 and 6 show the maximum values of displacements on the lining of the tunnel at dynamic time which are located at the crown with a maximum value equal to $0.533 \mathrm{~m}$ in the configuration 1 and 0,488 $\mathrm{m}$ in the configuration 2 . For the configuration 3 these values increase to $0.5362 \mathrm{~m}$ in the tunnel 1 and $0,496 \mathrm{~m}$ in the tunnel 2.

The maximum axial forces on the lining are illustrated in figures 7,8 and 9, with the value of $731(\mathrm{KN})$ in configuration 1, and 596(KN) in configuration 2 . Concerning the configuration 3 , we have a decrease to $584(\mathrm{KN})$ in tunnel 1 and an increase to $707 \mathrm{KN}$ in tunnel 2.The distribution of the bending moment in the figures 10, 11 and 12 can be observed. The maximum values prove the decrease from 248 KN.m in tunnel 1 (single) to 223 KN.m in the case of twin tunnels and the increase from 181 KN.m in tunnel 2 (single) to 222 KN.m in case of twin tunnels.

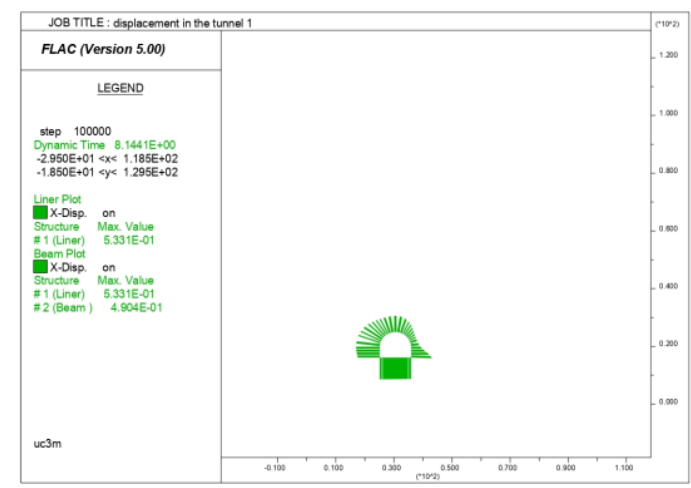

Fig.4 .The maximum displacements in tunnel 1

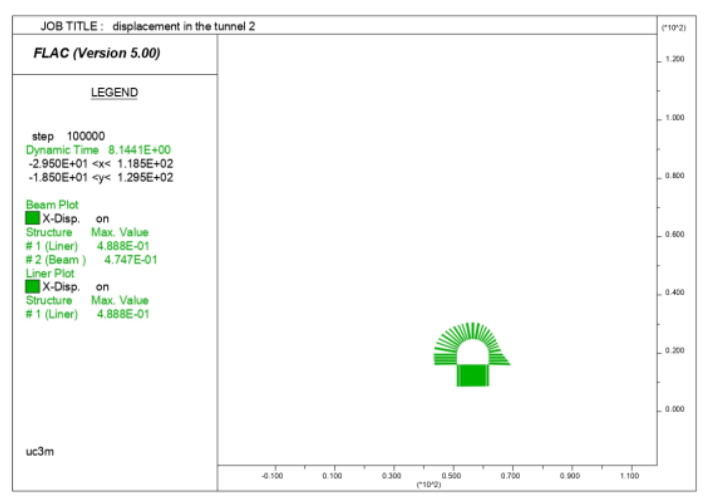

Fig.5. The maximum displacements in tunnel 2

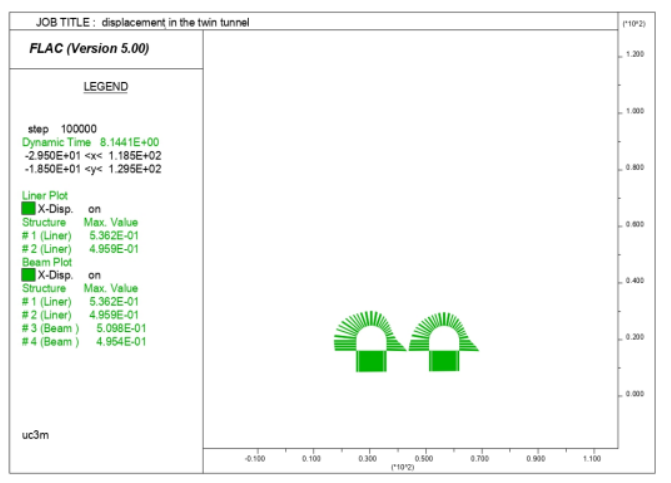

Fig.6.The maximum displacements in twin tunnels

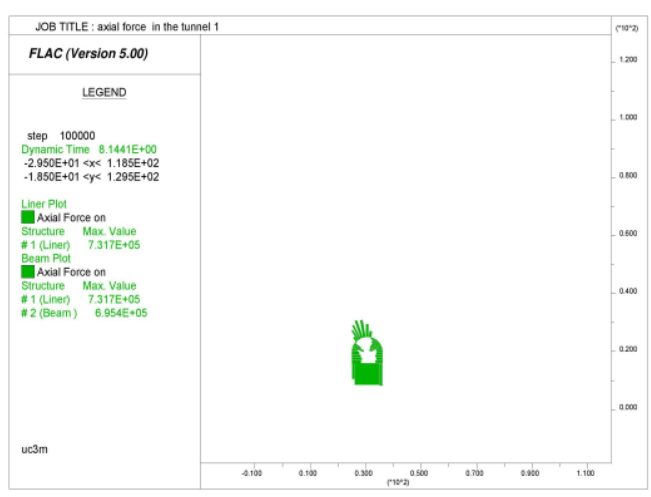

Fig.7. The maximum axial force in tunnel 1

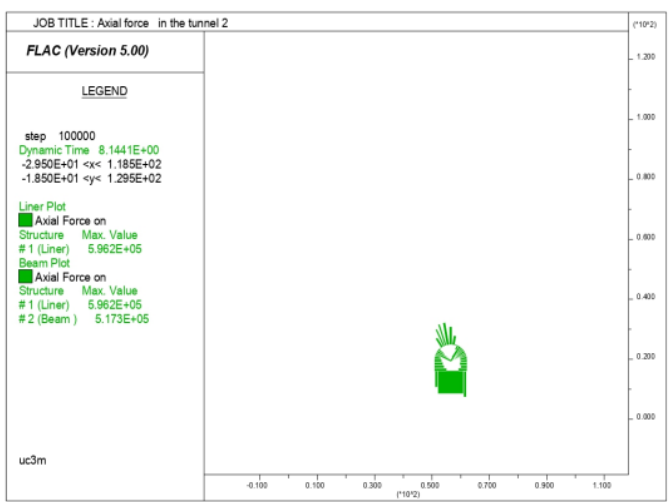

Fig .8. The maximum axial force in tunnel 2 


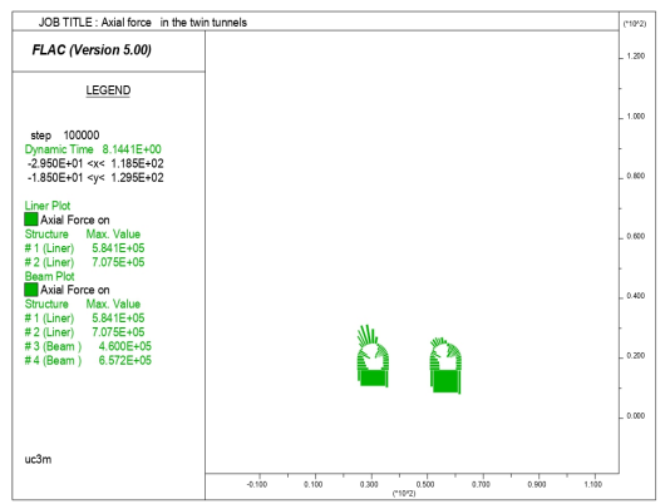

Fig.9. The maximum axial force in twin tunnels

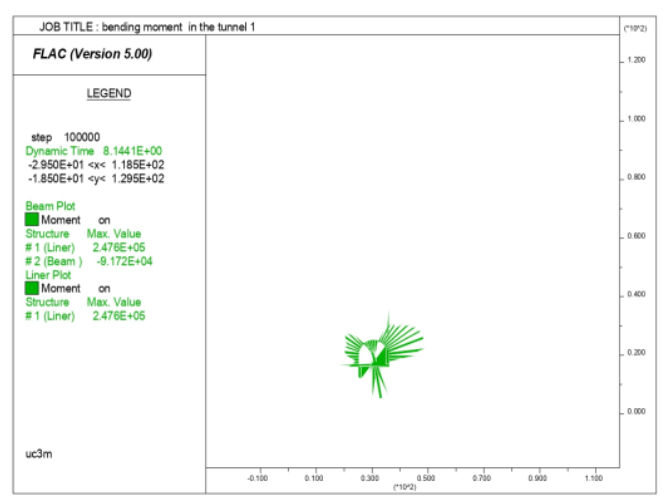

Fig .10. The maximum bending moment in the tunnel 1

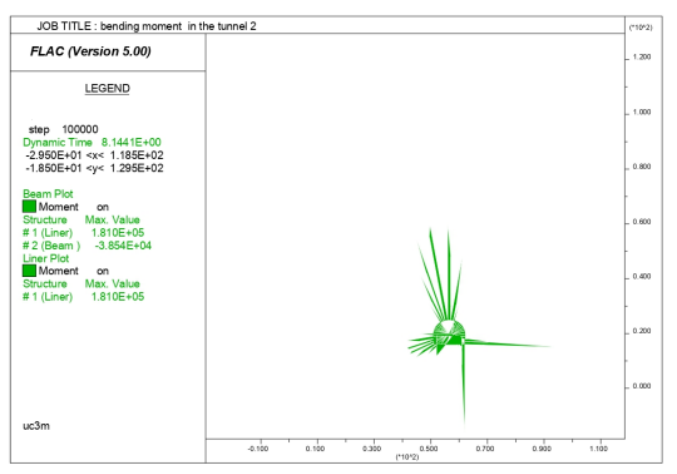

Fig.11.The maximum bending moment in tunnel 2

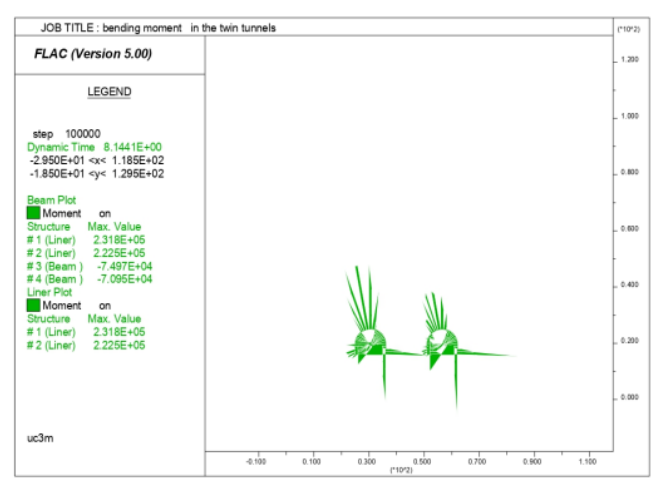

Fig.12. The maximum bending moment in twin tunnels
Table.3.The maximum values of the displacement, axial force and bending moment for different configurations

\begin{tabular}{|c|c|c|c|c|}
\hline \multirow[t]{2}{*}{ Configuration } & \multirow{2}{*}{$\begin{array}{c}\text { Tunnel } \\
1\end{array}$} & \multirow{2}{*}{$\begin{array}{l}\text { Tunnel } \\
2\end{array}$} & \multicolumn{2}{|c|}{ Twin tunnels } \\
\hline & & & $\begin{array}{c}\text { Tunnel } \\
1\end{array}$ & $\begin{array}{l}\text { Tunnel } \\
2\end{array}$ \\
\hline Max : Displacement (m) & 0,533 & 0,488 & 0,536 & 0,495 \\
\hline Max : Axial Force (KN) & 731 & 596 & 584 & 707 \\
\hline $\begin{array}{l}\text { Max : Bending moment ( } \\
\text { KN.m) }\end{array}$ & 248 & 181 & 223 & 222 \\
\hline
\end{tabular}

The compared values of the maximum displacement in table 3 show that differences up to $0.6 \%$ in tunnel 1 and $1.43 \%$ in tunnel 2 .

The maximum values of the axial forces and the bending moment respectively show that differences are down to $20.10 \%$ and to $10.08 \%$ in the tunnel 1 also those differences are up to $18.62 \%$ and to $22.65 \%$ in the tunnel 2.

These differences are justified by the interaction between the twin tunnels under seismic loading of El Centro earthquake in order to prove the efficiency of the proposed numerical model. However, the maximum values of the displacement, axial force and the bending moment during construction and service of the tunnel would be under the maximum calculated.

\section{Conclusions}

In this paper, the numerical simulations under seismic loading of El centro 1940 earthquake for the ZAM twin tunnels of Agadir motorway in Morocco have been used for the three configurations : tunnel 1 without tunnel 2 ,tunnel 2 without tunnel 1 and tunnel 1 with tunnel 2, using the differences element method provided by the FLAC $2 \mathrm{D}$ code. The model was built with linear elastic-perfectly plastic soil with an absorbing boundary for a good estimation of the interaction between the twin tunnels through the calculation of the maximum displacement, axial force and bending moment on the structure elements.

The comparative study shows that the maximum value differences are very noteworthy between the different configurations ,especially for the axial force and bending moment:

Displacements, the differences up to $0.6 \%$ in tunnel 1 and $1.43 \%$ in tunnel 2 .

Axial force

-The differences down to $20.10 \%$ in tunnel 1

-The differences up to $18.62 \%$ in tunnel 2

Bending moment:

-The differences down to $10.08 \%$ in tunnel 1

-The differences up to $22.65 \%$ in tunnel 2

\section{Prospects}

This study will allows us to:

-Evaluate the tunnel's performance under seismic conditions in terms of stress and strain to choose the 
support type of the twin tunnels and comparing with the type used in situ.

-Determine the damage that will affect the twin tunnels during a real seismic activity with suggested solutions

\section{References}

1. H. Iida, T. Hiroto, N. Yoshida, M. Iwafuji, Soils Found, Damage to Daikai subway station. Spl issue on geotech aspects of the January 171995 Hyogoken-Nanbu earthquake,283-300 (1996).

2. S.Nakamura, N.Yoshida., T.Iwatate, Japan Society of Civil Engineers, Committee of Earthquake Engineering, Damage to Daikai subway station during the 1995 Hyogoken-Nambu earthquake and its investigation, pp. 287-295 (1996).

3. WL. Wang, TT. Wang, JJ. Su, CH. Lin, CR. Seng, TH.Huang, Tunn Underg Sp Techno, Assessment of damage in mountain tunnels due to the Taiwan ChiChi earthquake. 16: 133-150(2001).

4. T.D .O’Rourke, S.H.Goh, C.O. Menkiti, R.J. Mair, Proceedings of the 15th Intern Conference on Soil Mechanics and Geotechnical Engineering, August 27-31, Istanbul, Highway tunnel performance during the 1999 Düzce earthquake.(2001).

5. M.Azadi ,M.Kalhor, World academy of science, Engineering and technology ,I jr of geolog and environ Engineering ,Study of the effect of seismic behavior of twin tunnels position on each other ,Vol:8 ,No6 (2014).

6. H. Alielahi, M. Adampira, I Jr of Rock Mechanics and Mining sciences, Effect of twin-parallel tunnels on seismic ground response due to vertically inplane waves, volume 85, page: 67-83 (2016).

7. S.Vijayakumar, M.Raj, T.A.Yohannan, International journal of advance Engineering and Research development,Finite element analysis of underground twin tunnel subjected of seismic forces, Volume 3,Issue 7 ( 2016).

8. C.C.Lu, J.H.Wang, Tunnelling and Underground Space Technology, Nonlinear collapse simulation of Daikai Subway in the 1995 Kobe earthquake: Necessity of dynamic analysis for a shallow tunnel volume 87 page 78-90 (2019).

9. L.Callisto, C. Ricci, Tunne and Undergr Sp Techno ,Interpretation and back-analysis of the damage observed in a deep tunnel after the 2016 Norcia earthquake in Italy, volume 89,page 238-248 (2019).

10. F.Medina, T-E Cherkaoui, Geophysica,Precisions sur mécanisme du foyer du séisme d'Agadir (Maroc) du 29 février 1960,place dans le cadre du sismotectonique du Maroc, Vol 24,Nos 1-2,PP 5666 (1988).

11. P.Cundall, Itasca Consulting Group, FLAC, v.5.00 User's Manual (2005). 